\title{
correspondence
}

\section{What is unusual?}

SIR,--In Sakurai's interesting discussion of the relation between equatorial solar rotation and climatic changes (29 September, page 401), a rather unfortunate choice of terminology is used in referring to "the Earth's present unusual climatic conditions". Unusual by what standard? The best evidence of available data covering the past 1,000 years or so suggests that the period roughly from the 1920s to the 1960 s was the most unusual 50-year period of the entire millennium, in climatic terms, at least for northwest Europe (H. H. Lamb, Climate: Present Past and Future, vol 2 (Methuen, 1977)). Studies such as that of Eddy (Scient. Am. 230, $80-92,1977)$ indicate that this was also an unusual period in sunspot terms, with very high peak sunspot numbers, in line with the general conclusions of Sakurai, Volland (28 September, page 400) and others.

The possibility of a return of climate towards nineteenth century conditions should not be regarded as 'unusual' climate except on the scale of a human lifetime; the unfortunate coincidence that an explosive growth of population and demand for food has happened over just that time makes it all the more important for us to develop an understanding of what really is 'normal' in climatic terms, and I would therefore urge Sakurai and other workers in this field to avoid misleading use of emotive terms such as "unusual". If the relevant sentence is rephrased to say "variation of the equatorial rotation speed may be responsible for the recent unusual climatic conditions on Earth, now returning to the normal conditions of recent centuries" the implications of the change for the activities of mankind are much more clearly apparent. JoHN GRIBBIN

Science Policy Research Unit, University of Sussex, UK

\section{Missions to Halley's comet}

SIR,- The informative article by David Hughes (11 August, page 468) concerning the proposed fly-by and rendezvous missions to Halley's Comet was, unfortunately, less than fair to the achievements of those who have been striving to perfect various space electric propulsion techniques.
In particular, his description of ion drive and solar-sail propulsion as two mechanisms (that) are still at the theoretical stage ..." is certainly far from true of ion propuision systems.

Several laboratories in the USA and in Europe have devoted many years of effort to developing ion thrusters of different kinds. The electron bombardment ionisation type, originally devised by Kaufman, has emerged as firm favourite, at least in the USA and the UK, and several versions are now ready for space qualification. These include the $10 \mathrm{~cm}$ diameter, $10 \mathrm{mN}$ thrust $\mathrm{T} 5$ device developed by the Royal Aircraft Establishment, with assistance from the UKAEA Culham Laboratory and British industry, and two thrusters of 8 and $30 \mathrm{~cm}$ diameter, produced by Hughes Research Laboratories under a programme directed by the NASA Lewis Research Center.

The highly-efficient $30 \mathrm{~cm}$ thruster is particularly well-suited to cometary rendezvous missions. Its thrust of about $130 \mathrm{mN}$ is appropriate to a multiple thruster, modular propulsion unit concept, with power being derived from solar arrays. This principle readily allows a wide range of throttling to match the available power as the distance of the spacecraft from the sun varies.

The application of this thruster to cometary missions has already been studied in great depth, particularly with regard to Comet Encke, and detailed designs have been produced of the necessary flight systems.

It should also be pointed out that, far from being "at the theoretical stage", two Kaufman-type ion thrusters were flown experimentally as early as 1970. They then operated successfully for $3,763 \mathrm{~h}$ and $2,011 \mathrm{~h}$. In 1976 , one was still capable of being run under its design conditions, whilst the other exhibited a single fault.

Space Department,

D. G. FEARN

Royal Aircraft Establishment

Farnborough, UK

\section{Engineers' salaries}

SIR,- In your editorial 'Room at the top--for whom?' (22 September, page 275), you quoted, from our report to the British Association Coordinating Group, some figures concerning salaries of engineers compared to other pro- fessional groups in manufacturing industry. The inference you draw, that salaries in production industry ". . . discriminate against the scientist and engineer . .", is exactly what the graphs of median age/earnings profiles appear to show, but the point we wished to bring out was that this inference is not justified.

The graphs were of median and upper quartile salaries by age for all the professional staff $(22,400)$ in a number of leading companies. Within this total, there were 7,386 engineers compared to 607 chartered accountants and only 141 lawyers, and we were careful to give the number in each professional group. Chartered accountants are trained, and in general gain their early experience, outside industry. A limited number are recruited by industry for functions which of their nature are mainly concerned with matters at or close to Board level. By contrast, as we show elsewhere in the report, the majority of graduate engineers initially go into industry, and industry also has an overwhelming stake in those who qualify via $\mathrm{HNC/}$ HND and institution membership. They are employed in a wide range of jobs, from basic technical work to Board level.

Therefore, if industry succeeds in its normal job evaluation objective, to pay comparable salaries for comparable jobs, small groups of professionals selectively employed by industry will show higher median or upper quartile age/earnings profiles than a large group of professionals generally employed. It is tempting to believe that upper quartile, and in particular upper decile, graphs will show a fair comparison, but unless the samples are carefully matched in each age group this is not so.

Using exactly the same salary data, we went on to look at the number in each professional group earning salaries on or above $£ 10,000$ a year. This is one way for the companies in the survey, of answering your headline question "Room at the top-for whom?". The 749 engineers enjoying these salaries represented only $10.1 \%$ of their group, but they outnumbered the accountants, lawyers, economists and arts graduates put together.

\section{VINCENT EDKINS}

The University of Aston

in Birmingham, $U K$ 